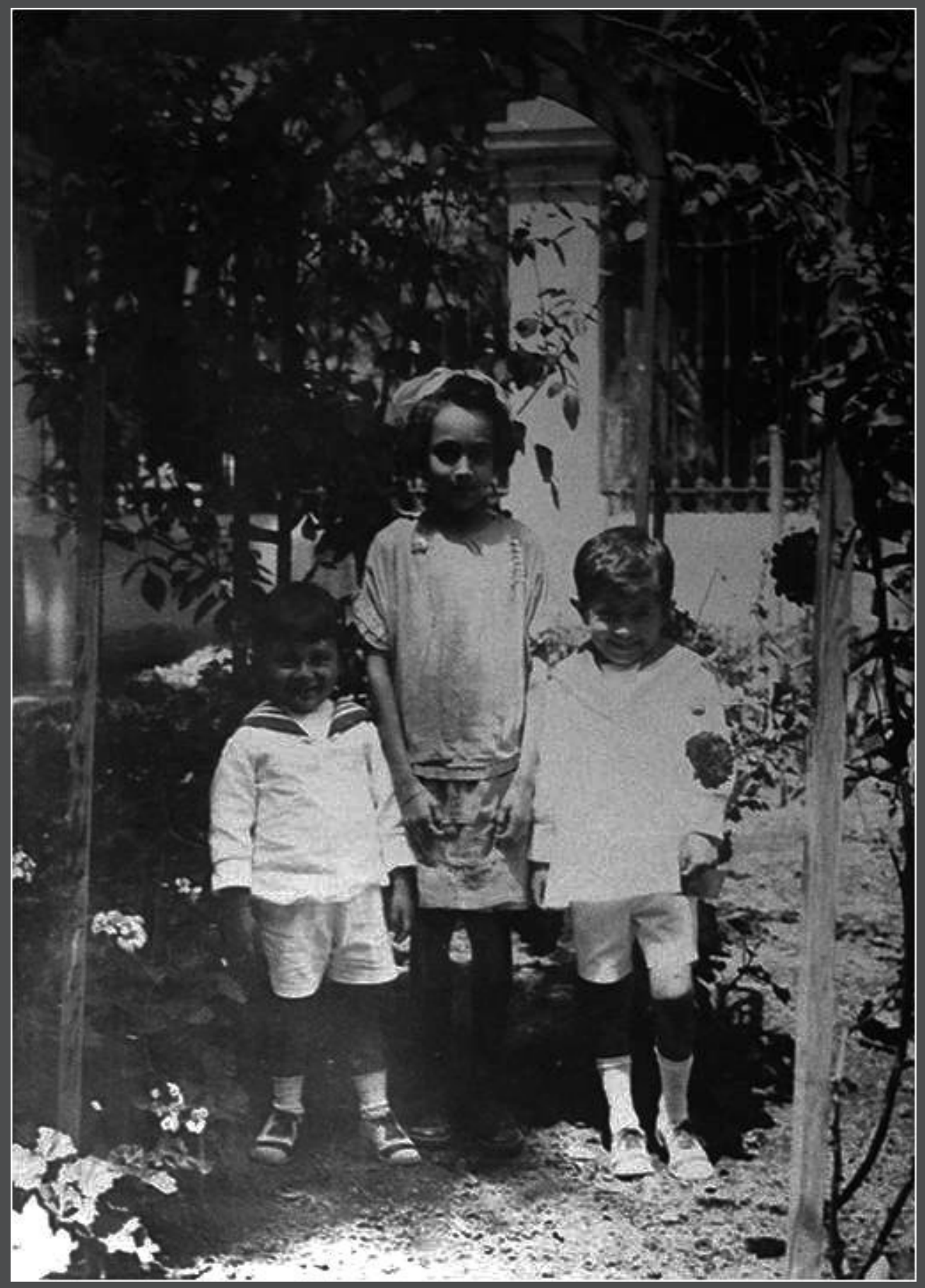

Iturriaga, niño (der.), junto a su hermano José y su prima Natalia Seoane.

Miraflores, 1922. Fuente: Archivo Enrique Iturriaga 


\section{Testimonio \\ El sentimiento nacional en la música culta: la obra de Enrique Iturriaga Romero}

Guillermina Maggiolo Dibos

\section{Introducción}

La renovación de la música en el siglo XX es uno de los fenómenos que más ha contribuido a afianzar el sentimiento nacional en el Perú contemporáneo. De manera especial, una nueva generación de compositores nacidos en diferentes regiones del país entre las décadas de 1910 y 1930 , va a aportar con la incorporación de elementos de raíces locales en la creación de obras de música culta. A este connotado grupo de músicos pertenece un autor cuya trayectoria marca un hito en la historia musical del país: Enrique Iturriaga Romero.

Nos proponemos establecer, en el presente trabajo, las raíces inspiradoras que lo condujeron a crear su importante obra, desentrañando así, influencias del mundo tradicional peruano y de la cultura occidental, descubriendo el evidente sincretismo existente en las creaciones de este gran artista limeño contemporáneo.

\section{Primera formación}

Nacido en Lima el 3 de abril de 1918, Enrique Iturriaga Romero fue el mayor de dos hermanos hombres, nacidos del matrimonio del arequipeño Juan Enrique Iturriaga Vidal y María Irene Romero Elguera, natural de Huacho.

El mundo sufre aún, por entonces, los estragos de la Primera Guerra Mundial. Es el último año de aquella primera gran conflagración a escala global, de cuyas cenizas iba a emerger un mundo nuevo, regido por el surgimiento de nuevas democracias en occidente, bajo el indiscutible liderazgo de los Estados Unidos de Norteamérica. 
El Perú, entretanto, atraviesa todavía por el periodo conocido como la República Aristocrática, caracterizada por el predominio de dos partidos en la escena política nacional: el Civil y el Demócrata. El primero llegaría a la presidencia en cinco ocasiones, mientras que el Demócrata, a pesar de su activa presencia en la vida política nacional, lo haría en un solo mandato.

La República Aristocrática llega a su fin al ascender al mando de la nación Augusto B. Leguía, tras comandar un golpe de Estado en 1919, aduciendo la amenaza de un supuesto fraude electoral. Este acontecimiento da paso al inicio del periodo histórico de once años conocido como el "Oncenio de Leguía".

Enrique Iturriaga, por el trabajo de su padre, vivió de niño en Huacho, al norte de la capital, donde creció junto a sus padres y abuelos maternos. En dicha ciudad radicaron cerca de diez años y fue allí donde se dio su primer contacto con la música.

Su padre tocaba piano y componía valses. En casa tenían un piano que era propiedad de su abuela. Desde los cuatro años de edad, el entonces niño Iturriaga jugaba con las teclas: primero con un dedo, luego con dos y tres, y, eventualmente, llegó a tocar de oído con los diez dedos.

En Huacho, la familia vivía cerca de una desmotadora de algodón, y el sonido y los ritmos de las diferentes ruedas, grandes y pequeñas, de su complejo mecanismo, llegó a fascinarlo. Así nació su primera composición, La máquina, que realizó a los catorce años, sin saber leer ni escribir música.

Regresando a Lima, ya adolescente, empezó a estudiar música de manera particular. Entre los catorce y veinte años estudió piano con Lily Rosay y se inició en teoría y solfeo con Andrés Sas. Ambos eran músicos belgas que llegaron al Perú en aquella época y fundaron una academia de música en Miraflores.

Iturriaga empezó sus estudios musicales de manera formal con la lectura musical, cuya realización le costaría, inicialmente, gran trabajo. Así, este aprendizaje fue de manera gradual. Se identificó con el estudio de la armonía. Comenta, en una entrevista que le hiciera Armando Sánchez Málaga, que le gustaba la composición, pero que Sas era muy ortodoxo para la enseñanza de la música, estando descontento con ese método de aprendizaje (Sánchez Málaga, 1991).

Sintió, por entonces, preferencia por la música del periodo romántico del siglo XIX y la música contemporánea del siglo XX. Con Rosay tocó obras de Rachmaninov, compositor romántico; y de Debussy, compositor impresionista posromántico, antes de ingresar al Conservatorio Nacional de Música.

Algo decisivo en su formación fue el acercamiento que tuvo hacia la música culta, al asistir con su madre a conciertos con la Orquesta Sinfónica Nacional, experiencia que le permitió escuchar al pianista Arthur Rubinstein y a renombrados guitarristas, así como solistas. También fue de gran importancia en su formación el haber asistido de manera regular a los ensayos de la Orquesta Sinfónica Nacional en el Teatro Municipal de Lima.

\section{La Segunda Guerra Mundial y sus implicancias en el quehacer musical nacional. El aprendizaje académico con Buchwald y Holzmann}

El maestro contaba con 21 años cuando se inicia la Segunda Guerra Mundial, acontecimiento que influye de manera indirecta en el quehacer musical peruano.

Así, entre los años 1934 y 1939, gran cantidad de músicos europeos salieron de sus ciudades huyendo de la amenaza nazi que se cernía sobre Europa, para refugiarse en Latinoamérica. Entre ellos, se contarían a figuras de la música luego destacadas en nuestro medio, como 
Theo Buchwald, Hans Prager, Bronislaw Mitman, Hans Levitus o Rodolfo Holzmann.

Particularmente, Buchwald tuvo un rol protagónico en un acontecimiento importante en la historia de la música nacional. Así, bajo su dirección, se funda en 1938 la Orquesta Sinfónica Nacional del Perú, con sesenta y cuatro músicos a su cargo, dentro de los cuales treinta eran europeos, en su mayoría judío-alemanes e italianos, precisamente aquellos que habían llegado huyendo de la guerra en el viejo mundo.

El profesor alemán Rodolfo Holzmann fue otro de aquellos músicos que vinieron al Perú en aquellas circunstancias. Tocaba en la fila de segundos violines de la Orquesta Sinfónica Nacional y fue profesor de composición en el Conservatorio Nacional de Música. César Arróspide de la Flor, musicólogo, profesor de la Universidad de San Marcos y creador de la cátedra de Historia de la Música, en la especialidad de Historia del Arte, de la Facultad de Letras de la Universidad de San Marcos,

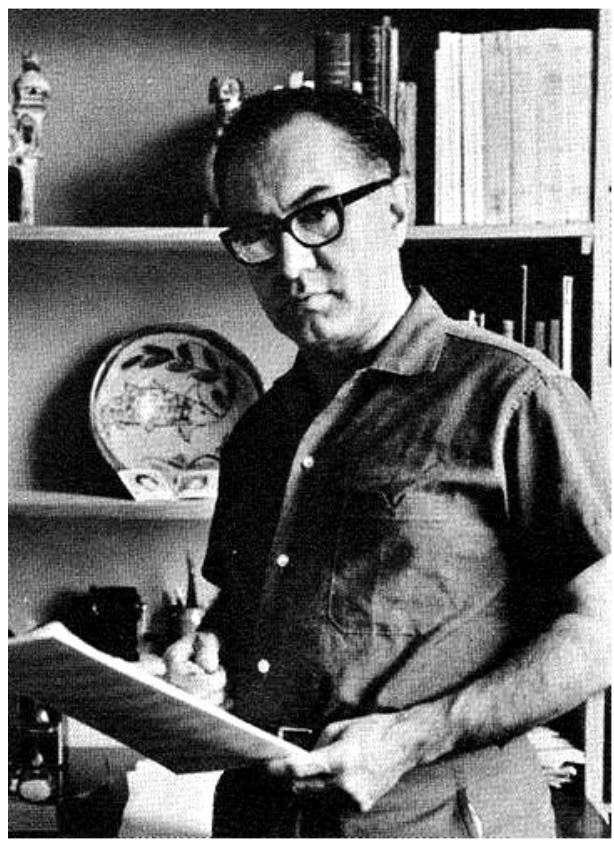

El compositor en 1963.

Fuente: Revista Fanal (Volumen 18, N. ${ }^{\circ} 68$ ) le recomendó a Iturriaga como maestro de composición a Holzmann, quien lo aceptó de inmediato como alumno.

En 1943, cuando se funda el Conservatorio Nacional de Música, Holzmann pasa a ser profesor de Composición en esa institución y lleva a Iturriaga a estudiar con él hasta 1950. Iturriaga, entretanto, animó a Celso Garrido Lecca y a Rosa Alarco para que estudiaran también en dicha nueva institución académica, siendo así compañeros en la carrera de composición musical. Luego entró a estudiar la misma carrera, Enrique Pinilla.

Todos ellos fueron alumnos de Holzmann y compañeros de Iturriaga hasta que terminaron sus estudios, en un periodo de cinco años en total. Asistían a los conciertos de la Orquesta Sinfónica Nacional y a los ensayos de dicha agrupación musical en el Teatro Municipal.

La verdadera formación de compositor de Iturriaga empieza con Holzmann, porque fue él quien lo hizo entrar en sí mismo. El maestro alemán, al enseñarles composición, preguntaba a sus alumnos el significado de cada una de las notas que colocaban en el pentagrama. Cada nota de la composición musical debía proceder de alguna vivencia o idea, y era muy importante que fuera identificada, haciendo del proceso de composición un ejercicio consciente.

Iturriaga quiso entonces explorar otras formas de expresión musical y empezó a tocar al piano la música impresionista, la música romántica y la moderna, antes de 1950.

Fue después de esta etapa que se acercó a la música del periodo clásico, siendo su primer referente Mozart y, posteriormente, Beethoven. Finalmente, apreciamos que Iturriaga comprendió la música de los siglos XIX y XX antes que la música clásica del siglo XVIII.

\section{Su encuentro con las raíces musicales peruanas: Arguedas}

En 1952, Iturriaga regresa a Lima después de un año de estudios de composición en París. Por aquellos días, empezó a conocer las obras de algunos compositores contemporáneos 


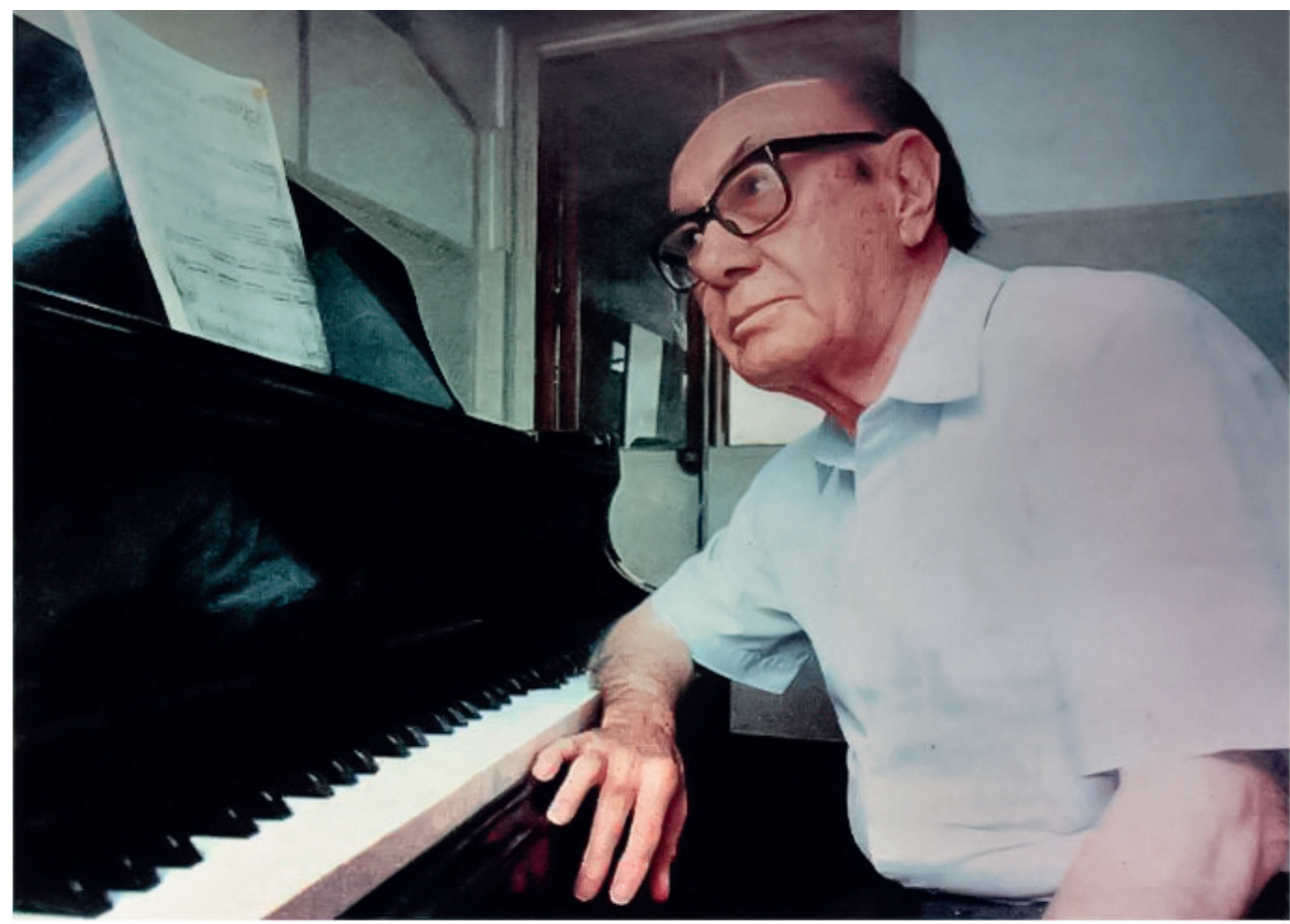

Enrique Iturriaga. Fuente: Archivo Enrique Iturriaga

peruanos, despertándose así su preferencia por la música nacional, muy importante para él desde entonces.

Su amistad con el conocido escritor y etnólogo José María Arguedas empezó cuando este vio a Iturriaga dirigiendo un coro en el puericultorio Pérez Araníbar. La relación con Arguedas lo acercó, de manera significativa, a las expresiones musicales vernáculas, tomando contacto directo con los festivales de música andina en nuestra capital.

A lo largo de tres años, Arguedas lo llevó a visitar el Coliseo Cerrado de la avenida 28 de julio en La Victoria, donde cada domingo se realizaban festivales de música folklórica con diversos grupos procedentes de distintas partes del país, enseñándole el gran escritor apurimeño a distinguir el valor artístico de cada uno de ellos.

Esta es una influencia que enriquecerá su expresión, incorporando a ella el espíritu andino de la música pentafónica, herencia de nuestro pasado prehispánico.

Particularmente, Iturriaga le da mucho valor al hecho de haber viajado innumerables veces con José María Arguedas a Tupe, distrito de la provincia de Yauyos en la sierra de Lima, y a otros lugares de la sierra, lo que explica la influencia que ejerció la música andina en su obra.

Según él, en estas experiencias pudo sentir, a través de los paisajes, de los cantos de las aves y de la música tradicional que escuchaba, el profundo sentimiento del hombre andino, lo cual le sirvió de gran inspiración.

Esta inspiración que Iturriaga manifiesta haber sentido luego de los viajes con Arguedas, está magistralmente expresada en Las cumbres, que evoca, en sugestivo nombre, los variados y pintorescos paisajes de la sierra peruana. 
El maestro manifiesta que aquellos viajes y el conocimiento de la música popular al lado de Arguedas, al igual que el inspirador amor de Holzmann por la música tradicional del Perú, fueron los que lo inclinaron, en sus trabajos creativos, hacia el mundo místico y andino, a pesar de haber nacido y vivido toda su vida en la costa del Perú.

De esta manera, el compositor llega a asumir el papel importante de mediador entre la “cultura popular" y la "cultura culta” (Burke, 1978), al ser un creador que se alimenta de la música folklórica peruana para transportarla a las esferas de la música culta. Iturriaga se convertiría, así, en uno de los compositores nacionales de música clásica que reflejaría, de manera más amplia, la gran diversidad cultural peruana.

Como menciona Hipólito Taine en su libro La naturaleza de la obra de arte, la obra de arte no está aislada y se debe de buscar el conjunto del cual depende y la explica (Taine, 1969). En este caso, Iturriaga utiliza elementos musicales tradicionales del Perú, como instrumentos, melodías y versos, así como técnicas de composición e instrumentos occidentales europeos. Como consecuencia, tendremos un tipo de arte que representa una nueva identidad musical, al fusionar de manera magistral, contenidos y formas locales y foráneas.

Por otro lado, al ser Iturriaga un compositor amante de la música romántica del siglo XIX, su obra incorpora, tal como ocurriera en Europa con los músicos de aquella corriente, el acentuado sentimiento nacionalista y la reivindicación del folklore y la cultura local.

Las pruebas evidentes del uso de melodías y ritmos tradicionales peruanos hacen que quienes escuchen su música se sientan cercanos y atraídos por manifestaciones que les son familiares. De esta manera, sus composiciones establecen un lugar común entre sus oyentes. Lugar común que nos une y nos hermana, al representar símbolos que nos permiten imaginar el concepto de nación, como acertadamente lo expresaría Benedict Anderson, en su libro Comunidades imaginadas (Anderson, 1993).

Iturriaga utilizará luego los conocimientos adquiridos a través de sus estudios académicos de música en el Conservatorio Nacional de Música y con el compositor Honneger en París para realizar grandes obras sinfónicas, sinfónico-corales, para coros mixtos y de diferentes géneros, donde introduce elementos de la música contemporánea europea, unidos, ahora, con elementos peruanos.

Así ocurre con el Homenaje a Stravinsky, donde emplea una orquesta sinfónica sin violines ni violas y tiene como solista a un cajón peruano, materializando así, una idea innovadora. En este caso, el uso del cajón es una clara alusión a la fusión cultural criolla, a través del componente afroperuano. También encontramos como muestra significativa de sus motivaciones nacionalistas sus composiciones de huaynos de Navidad y de arreglos que efectúa a huaynos compuestos por Holzmann, acercándose así, una vez más, a la música de los andes.

De igual forma, el compositor arregla para coros polifónicos obras populares como el vals Estrellita del sur. En su obra Pregón para piano escuchamos en una versión moderna los cantos de los pregones que vendían "revolución caliente" por las tradicionales calles de la Lima de antaño.

Así, su obra nos permite permanentemente rememorar hechos de nuestra cultura que, en algunos casos, han ido desapareciendo y que, a través de la tradición, se mantienen vivos a lo largo de los años.

\section{Algunos trabajos emblemáticos}

Siendo todavía alumno del Conservatorio Nacional de Música, obtuvo el premio nacional “Luis Dunker Lavalle” por su obra Canción y muerte de Rolando, para soprano y orquesta, que 
la Orquesta Sinfónica Nacional estrenó en 1949, bajo la dirección de Theo Buchwald, con la soprano Gloria Colmenares como solista. Gracias al premio recibido por su obra, Iturriaga obtuvo la beca para estudiar un año composición en Francia.

Canción y muerte de Rolando es la primera obra dramática compuesta por un músico formado en el Perú por Holzmann en el Conservatorio Nacional de Música. Es una obra que Iturriaga considera muy auténtica.

En 1951, Iturriaga se graduaría en el Conservatorio Nacional de Música como profesor de composición, labor que llevaría a cabo en dicha institución, de manera ininterrumpida, durante toda su vida.

Luego de estudiar en Francia, gracias a la beca obtenida por el primer premio de composición, regresa al Perú en 1952, dedicándose a la composición, a la enseñanza y a la dirección de coros.

Dirigió coros en el colegio Guadalupe y en el puericultorio Pérez Araníbar. Primero un coro de varones, luego uno de mujeres y, finalmente, un coro mixto.

En 1957, con ocasión del II Festival Latinoamericano de Caracas, un jurado integrado por Aaron Copland, Carlos Chávez, Alberto Ginastera, Juan Bautista Plaza y Domingo Santa Cruz, le otorgó, por su Suite para Orquesta, el premio "Juan Landaeta”. Carlos Chávez dirigió el estreno de la obra en Caracas y, al año siguiente, 1958, se estrenó en Lima con la Orquesta Sinfónica Nacional.

En 1965, el comité para el III Festival Interamericano de Washington, le encargó una obra sinfónica. Compuso, entonces, Vivencias, cuatro piezas para orquesta que fue estrenada por Lukas Foss y la Orquesta Sinfónica de Buffalo. En 1966, Luis Herrera de la Fuente dirigió en Lima Vivencias con la Orquesta Sinfónica Nacional.

En 1971 obtuvo por segunda vez el premio "Luis Dunker Lavalle", por su obra Homenaje a Stravinsky, para orquesta con cajón solista, estrenada por la Orquesta Sinfónica Nacional, bajo la dirección de Luis Herrera de la Fuente, ese mismo año.

\section{La Sinfonía Junín y Ayacucho}

Sería, sin embargo, en 1974, cuando obtendría uno de los mayores logros de su carrera musical. Ese año se hace acreedor, por su Sinfonía Junín y Ayacucho, del primer premio del Concurso de Composición Sinfónica convocado por el Ejército del Perú en conmemoración del sesquicentenario de Junín y Ayacucho, batallas que sellaron la independencia hispanoamericana en 1824. Esta sinfonía fue estrenada y grabada por la Orquesta Sinfónica Nacional, bajo la dirección de Armando Sánchez Málaga.

Los contundentes acordes de los cuatro movimientos de la Sinfonía Junín y Ayacucho hacen posible transportarnos, indistintamente, a un bello amanecer andino o a los mismos fragores del combate, imágenes que evocan escenarios y acciones de las gloriosas campañas militares del Ejército Unido Libertador de Bolívar en el Perú.

Esta es una de sus obras cumbres, que, además de representar la imagen sonora de lo que fue un hecho histórico de relevancia mayor, nos recuerda, cada vez que la escuchamos, nuestra condición de hombres libres, miembros de una nación que ha luchado, por sus propios medios, por su independencia.

El hecho de llevar la Sinfonía Junín y Ayacucho, dentro de sus notas musicales, compases de las melodías del himno nacional del Perú, así como de ritmos que nos recuerdan la participación de diferentes regiones del país y de Sudamérica en la gesta por nuestra separación de la corona española, nos hace catalogar a esta obra como un símbolo musical de eminente contenido patriótico. 


\section{Maestro de nuevas generaciones}

En su faceta académica, entre 1973 y 1976, Enrique Iturriaga fue director de la Escuela Nacional de Música (hoy Conservatorio Nacional de Música). Fue, asimismo, profesor de la Pontificia Universidad Católica del Perú y de la Universidad Nacional Mayor de San Marcos, de la cual llegaría a ser profesor emérito. En 1999 fue elegido, por segunda vez, como director general del Conservatorio Nacional de Música.

La enseñanza ha sido la actividad a la que más tiempo ha dedicado. Sin embargo, siempre supo alternar el ejercicio de la docencia con la composición, la investigación y la escritura. Esto nos habla de un maestro y músico integral, combinación muy poco frecuente. El prototipo de un artista y docente, a la vez.

Siendo Iturriaga uno de los compositores más importantes de la segunda mitad del siglo XX en el Perú, ha sido un gran educador, formando, entre sus alumnos, a músicos peruanos muy destacados en las últimas décadas, como Walter Casas, Seiji Pedro Asato, Douglas Tarnawiecki, Miguel Harth Bedoya o Andrés Santa María, entre muchos más.

En la entrevista que le hiciera Raúl Vargas en su programa Peruanos en su Salsa (2010), Iturriaga menciona que, sacando la cuenta, debe de haber tenido cerca de treinta mil alumnos a lo largo de su vida, lo cual nos habla acerca del enorme alcance que sus enseñanzas han tenido sobre varias generaciones de exponentes de la música local.

\section{Cómo entender a Iturriaga}

Su música emplea la técnica europea de composición y también instrumentos occidentales, como la orquesta sinfónica y el coro polifónico. Sus referentes occidentales incluyen obras de los primeros siglos de la escritura musical, del Canto Gregoriano, de la música barroca del s. XVII, de la del periodo clásico del s. XVIII, de la romántica del s. XIX, y de la moderna y contemporánea del s. XX.

Finalmente, a ello se une, en una original fusión, la presencia de la pentafonía tradicional andina peruana (en la que encuentra un paralelo con la música del compositor Arnold Shoenberg) y, en general, el acervo cultural nacional andino y costeño de distintas épocas, donde se hallan los sonidos del folklore: canciones y cuentos populares, costumbres y festividades religiosas, tradiciones del campo y de la ciudad.

Su obra fusiona todo ello en una gran expresión, concebida para orquestas, así como coros y orquestas, en múltiples e interesantes combinaciones.

Hoy, a sus cien años de vida, Iturriaga continúa siendo un compositor presente y consciente de su país y de su época. Es un artista responsable y coherente con la historia que le toca vivir, y piensa, con mucha convicción, acerca del rol que le compete a su labor creativa como expresión de la cultura. Respeta y ama lo suyo, ha estudiado y aprendido todo aquello que le ha permitido desarrollar su arte para ponerlo al servicio de su sociedad.

Y al ser, al mismo tiempo, un educador que dedicara gran parte de su vida enseñando en instituciones académicas importantes (como la Universidad Nacional Mayor de San Marcos, La Pontificia Universidad Católica del Perú, el Conservatorio Nacional de Música o la Universidad San Agustín de Arequipa), dictando cursos y conferencias en muchos lugares de América, así como escribiendo obras para diversos músicos del Perú y del extranjero, ha permanecido siempre consciente de la importancia de la formación cultural de las nuevas generaciones, así como del compromiso que estas deben de cumplir para con su sociedad. 


\section{Referencias bibliográficas}

Anderson, B. (1993). Comunidades imaginadas. Primera impresión en español. $3 .^{a}$ reimpresión. México: Fondo de Cultura Económica.

Burke, P. (1996). Cultura popular en la Europa Moderna. Madrid: Alianza Editorial SA.

Pinilla, E. (1988) La Música en el Perú: La Música en el Siglo XX. Lima: Patronato Popular y Porvenir Pro Música Clásica.

Quesada Macchiavelo, J. (1999). Compositores Peruanos del Siglo XX. N. ${ }^{\circ}$ 2. J.Q.M. (Editor). Lima: Centro de Estudios, Investigación y Difusión de la Música Latinoamericana de la Pontificia Universidad Católica del Perú.

Sánchez Málaga, A. (2012). Compositores Peruanos del Siglo XX. N. ${ }^{\circ}$ 12. A.S.M. (Editor). Lima: Centro de Estudios, Investigación y Difusión de la Música Latinoamericana de la Pontificia Universidad Católica del Perú.

Taine, H. (1969). La naturaleza de la obra de arte. México: Editorial Grijalbo, SA.

\section{Artículos y estudios en libros y revistas}

Pinilla, E. (1980). Procesos e Instituciones: Informe sobre la música en el Perú. En J. Mejía Baca (Editor), Historia del Perú, Tomo IX (pp. 363-657). Lima, Perú: Editorial Juan Mejía Baca.

\section{Referencias web}

Vargas, R. (2010) Peruanos en su salsa. Entrevista al compositor Enrique Iturriaga. Recuperado de http://youtube.com/watch?v=j4YOej9b7Uk

\section{Fuentes testimoniales}

Entrevista presencial a Enrique Iturriaga por Armando Sánchez Málaga. Archivo de la Imagen y la palabra. Fundación Edubanco (Banco Continental). Lima, octubre 2, de 1991. 